\title{
An Effective Water Body Extraction Method with New Water Index for Sentinel-2 Imagery
}

\author{
Wei Jiang ${ }^{1,2,3}$, Yuan $\mathrm{Ni}^{4}$, Zhiguo Pang ${ }^{1,2, *}$, Xiaotao $\mathrm{Li}^{1,2}$, Hongrun $\mathrm{Ju}^{5}$, Guojin $\mathrm{He}^{6}$, Juan $\mathrm{Lv}^{1,2}$, Kun Yang ${ }^{1,2}$, \\ June Fu ${ }^{1,2}$ and Xiangdong Qin ${ }^{1,2}$
}

1 State Key Laboratory of Simulation and Regulation of Water Cycle in River Basin, China Institute of Water Resources and Hydropower Research, Beijing 100038, China; jiangwei@iwhr.com (W.J.); lixt@iwhr.com (X.L.); lujuan@iwhr.com (J.L.); yangkun@iwhr.com (K.Y.); fuje@iwhr.com (J.F.); qinxiangdong1996@163.com (X.Q.)

2 Remote Sensing Technology Application Center, Research Center of Flood and Drought Disaster Reduction of the Ministry of Water Resources, Beijing 100038, China

3 Postdoctoral Workstation of China Reinsurance (Group) Corporation, Beijing 100033, China

4 Sichuan Highway Planning, Survey, Design and Research Institute Ltd., Chengdu 610041, China; niyuan_map@163.com

5 School of Tourism and Geography Science, Qingdao University, Qingdao 266071, China; juhr@qdu.edu.cn

6 Aerospace Information Research Institute, Chinese Academy of Sciences, Beijing 100094, China; hegj@radi.ac.cn

* Correspondence: pangzg@iwhr.com; Tel.: +86-01-68785406

Citation: Jiang, W.; Ni, Y.; Pang, Z.; Li, X.; Ju, H.; He, G.; Lv, J.; Yang, K.; Fu, J.; Qin, X. An Effective Water Body Extraction Method with New Water Index for Sentinel-2 Imagery. Water 2021, 13, 1647. https:// doi.org/10.3390/w13121647

Academic Editor: David

Pulido-Velázquez

Received: 6 May 2021

Accepted: 8 June 2021

Published: 11 June 2021

Publisher's Note: MDPI stays neutral with regard to jurisdictional claims in published maps and institutional affiliations.

Copyright: (c) 2021 by the authors. Licensee MDPI, Basel, Switzerland. This article is an open access article distributed under the terms and conditions of the Creative Commons Attribution (CC BY) license (https:// creativecommons.org/licenses/by/ $4.0 /)$.

\begin{abstract}
Surface water bodies, such as rivers, lakes, and reservoirs, play an irreplaceable role in global ecosystems and climate systems. Sentinel-2 imagery provides new high-resolution satellite remote sensing data. Based on the analysis of the spectral characteristics of the Sentinel-2 satellite, a novel water index called the Sentinel-2 water index (SWI) that is based on the vegetation-sensitive red-edge band (Band 5) and shortwave infrared (Band 11) bands was developed. Four representative water body types, namely, Taihu Lake, Yangtze River, Chaka Salt Lake, and Chain Lake, were selected as study areas to conduct a water body extraction performance comparison with the normalized difference water index (NDWI). We found that (1) the contrast value of the SWI was larger than that of the NDWI in terms of various water body types, including purer water, turbid water, salt water, and floating ice, which suggested that the SWI could achieve better enhancement performance for water bodies. (2) An effective water body extraction method was proposed by integrating the SWI and Otsu algorithm, which could accurately extract various water body types with high overall accuracy. (3) The method effectively extracted large water bodies and wide river channels by suppressing shadow noise in urban areas. Our results suggested that the novel method can achieve efficient water body extraction for rapidly and accurately extracting various water bodies from Sentinel-2 data and the novel method has application potential for larger-scale surface water mapping.
\end{abstract}

Keywords: Sentinel-2; water body extraction; spectral characteristics analysis; water index; Otsu algorithm

\section{Introduction}

As an important part of the global water cycle, surface water bodies have an irreplaceable role in global ecology and climate systems [1,2]. Surface water usually includes rivers, lakes, and reservoirs with obvious seasonal variations [3-5]. Therefore, the rapid and accurate monitoring of surface water is of great significance to hydrological processes and water resource management [6,7]. Unlike traditional field measurements, remote sensing imagery is macrographic, dynamic, and inexpensive and can obtain surface information in real time [8,9]. Therefore, remote sensing technology has been widely used in regionalscale and global-scale surface water mapping [10-12]. The methods of extracting water bodies from optical imagery include the single-band threshold method [13], water index 
method [14-16], remote sensing image classification method [17,18], mixed pixel decomposition method [19-21], and multisource data combination method [20,22]. However, considering the precision requirement and the complexity of the methods, the water index method is one of the most convenient and highly precise water extraction methods [23].

McFeeters made full use of the near-infrared (NIR) and visible light green bands of the Landsat Multispectral Scanner (MSS) data and proposed the normalized difference water index (NDWI). The index can effectively highlight the water body information and eliminate soil and surface vegetation, but it misses built-up areas [14]. In the referenced paper [15], Xu proposed the modified normalized difference water index (MNDWI) based on Landsat Thematic Mapper/Enhanced Thematic Mapper Plus (TM/ETM+) data, which can not only overcome the shortcomings of NDWI but also reveal characteristic information, such as the water environment. The multiband water index, namely, the automated water extraction index (AWEI), was built for Landsat TM data, which can further handle mountain shadows caused by the terrain that the MNDWI fails to eliminate [23].

Although these indices have good effects for water extraction from Landsat series satellites, a slight change in the spectral range of the corresponding wavebands for different sensors may lead to a change in the water extraction results. Therefore, modified waters have been widely explored for various satellite sensors [16,24]. In the referenced paper [25], the slope and NIR band are combined to construct the normalized difference vegetation index (NDVI) and NDWI and then the index is applied to HuanJing (HJ)-1A/B satellite images for water extraction; the result is then finally consistent with the MNDWI results based on the Landsat TM data. In the referenced paper [26], a water index, namely, the linear discriminant analysis water index (LDAWI), was proposed to identify water bodies in SPOT5 satellite imagery and the index achieved good performance with an overall accuracy of $98 \%$. For Gaofen- 1 satellite remote sensing imagery, the NDWI and modified two-mode method were combined to extract surface water and the results suggested that the proposed method has higher and stable mapping accuracy [27].

Sentinel-2 is a new satellite launched by the European Space Agency (ESA), which can obtain global satellite data with a wide width and multispectral band and has been successfully applied in surface water mapping [28-31]. Due to the multispectral advantage of Sentinel-2, the NDWI with threshold adjustment is a simple and effective method to extract water bodies [32,33]. In the referenced paper [33], the NDWI and MNDWI with different bands from Sentinel-2 was evaluated and the results suggested that object-level MNDWI with Band 11 can achieve feasible water extraction performance. Due to the different spatial resolutions between shortwave infrared (SWIR) bands and optical bands, spatial resampling or band sharpening should be conducted before calculating water indices [32,33]. Recently, different pansharpening algorithm comparisons of NDWI and MNDWI water indices were conducted. The à trous wavelet transformation (ATWT) with 10-m MNDWI yielded the best water body mapping results [32]. In the referenced paper [34], Yang et al. employed principal component analysis to sharpen the $10 \mathrm{~m}$ NDWI and the $20 \mathrm{~m}$ SWIR bands and, then, the SWIR band was sharpened with the green band to construct the MNDWI to identify exact water bodies. Although the sharpening method between SWIR bands and optical bands can be performed to balance the different spatial resolutions, the efficiency of water body extraction at a large scale will be limited.

Currently, most of the research has focused on existing water body indices and has not taken into account the unique vegetation-sensitive red-edge band of Sentinel-2. Therefore, this study first analyzes the spectral response mechanism of different land cover types for Sentinel-2 and then identifies the sensitivity bands of water bodies to calculate a novel NDWI. By testing various water types (freshwater lakes, coastal waters, salt lakes, and ice), the extraction performance and precision of the new index and the NDWI are compared. Finally, the application scope of the novel water index is discussed. This novel water index can assist the understanding of the dynamic changes in surface waters by utilizing large-scale surface water mapping. 


\section{Data Source}

In order to acquire land and coastal waters with high-resolution optical imagery, the European Commission and the ESA jointly developed the Sentinel-2 satellite mission under the Copernicus program [35,36]. The Sentinel-2 mission is composed of two satellite constellations (Sentinel-2A and 2B) running in sun-synchronous orbit. The orbit height is $786 \mathrm{~km}$, the inclination is 98.5 degrees, the revisit period is 5 days, and the design life is 7 years [28].

The payload of the Sentinel-2 satellites is a push-broom multispectral imager (MSI) and the payload parameter information is shown in Table 1. It has 13 channels, the spectral range is from $0.4 \mu \mathrm{m}$ to $2.4 \mu \mathrm{m}$, and the spatial resolutions are $10 \mathrm{~m}, 20 \mathrm{~m}$, and $60 \mathrm{~m}$ [37]. The Sentinel-2 data product is Level-1C (L1C) top-of-atmosphere (TOA) reflectance data processed by geometric correction. The download address for the data source is https: //scihub.copernicus.eu/dhus/\#/home (accessed on 9 March 2018).

Table 1. Payload parameter information of the Sentinel-2 satellites.

\begin{tabular}{ccc}
\hline Bands & Wavelength Range/ $\mathbf{m m}$ & Spatial Resolution/m \\
\hline Band 1-Coastal aerosol & $0.433-0.453$ & 60 \\
Band 2-Blue & $0.4575-0.5225$ & 10 \\
Band 3-Green & $0.5425-0.5775$ & 10 \\
Band 4-Red & $0.65-0.68$ & 10 \\
Band 5-Vegetation Red Edge 1 (VRE1) & $0.6975-0.7125$ & 20 \\
Band 6-Vegetation Red Edge 2 (VRE2) & $0.7325-0.7475$ & 20 \\
Band 7-Vegetation Red Edge 3 (VRE3) & $0.773-0.793$ & 20 \\
Band 8-Near-infrared (NIR) & $0.7845-0.8995$ & 10 \\
Band 8A-Vegetation Red Edge 4 & $0.855-0.875$ & 20 \\
Band 9-Water Vapor & $0.935-0.955$ & 60 \\
Band 10-Shortwave Infrared 1 (SWIR 1) & $1.36-1.39$ & 60 \\
Band 11-Shortwave Infrared 2 (SWIR 2) & $1.565-1.655$ & 20 \\
Band 12-Shortwave Infrared 3 (SWIR 3) & $2.1-2.28$ & 20 \\
\hline
\end{tabular}

The selection of study areas required the consideration that the experimental areas are representative and, thus, the water and nonwater types in the study areas should be abundant and diverse. Water bodies include rivers, lakes, reservoirs, offshore, and other conventional water bodies, as well as special water bodies containing sediment, salt, and ice. Nonwater bodies include vegetation, buildings, bare land, and other objects. According to the selection criteria, Taihu Lake, the Yangtze River, Chaka Salt Lake, and Chain Lake are selected as the experimental areas. Figure 1 shows the specific locations of the study areas and the land cover descriptions of the study area data are summarized in Table 2.

Table 2. The metadata and land cover descriptions of Sentinel-2A.

\begin{tabular}{ccccc}
\hline Study Area & Location & Satellite Type & Data Acquisition & Land Cover Description \\
\hline A & Taihu Lake & Sentinel-2A & 28 February 2017 & $\begin{array}{c}\text { River channel, lakes, and urban water bodies } \\
\text { surrounded by the vegetation and buildings. }\end{array}$ \\
\hline B & Yangtze River & Sentinel-2A & 28 February 2017 & $\begin{array}{c}\text { Rivers, offshore, and sediment-polluted } \\
\text { surrounded by the farmland. }\end{array}$ \\
\hline C & Chaka Salt Lake & Sentinel-2A & 30 July 2016 & Salt water surrounded by the bare land. \\
\hline D & Chain Lake & Sentinel-2A & 9 April 2017 & $\begin{array}{c}\text { Lake clusters and reservoirs surrounded by } \\
\text { the bare land and vegetation. }\end{array}$ \\
\hline
\end{tabular}




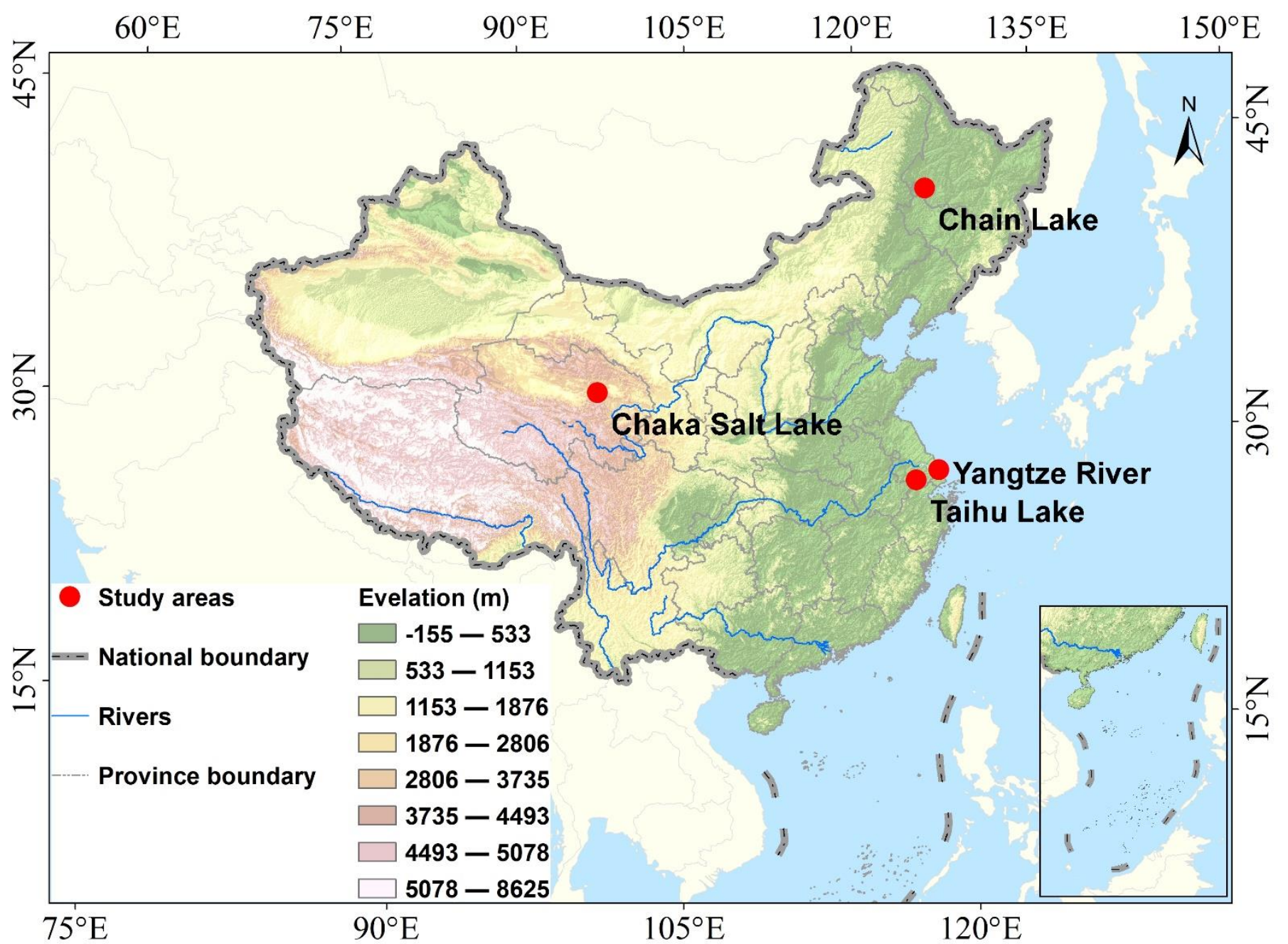

Figure 1. Locations of the study areas.

\section{Methods}

3.1. Analysis of the Spectral Response Mechanism

By using the difference in the reflectance values between the target objects in different bands, the brightness value of the target objects can be enhanced and the brightness value of the background objects will be suppressed. Based on this principle, McFeeters constructed the NDWI using green and NIR band extracted from the Landsat 5 data, which can effectively suppress soil and vegetation information and enhance water [14]. This formula is as follows.

$$
N D W I=\frac{\rho_{\text {Green }}-\rho_{N I R}}{\rho_{\text {Green }}+\rho_{N I R}}
$$

In the formula, $\rho_{\text {Green }}$ denotes the reflectance of the green band (Band 3 of the Sentinel-2 data) and $\rho_{N I R}$ denotes the reflectance of the near-infrared band (Band 8 of the Sentinel2 imagery).

$\mathrm{Xu}$ found that the buildings would be easily confused with water using NDWI due to the near-infrared band and the reflectance of buildings is suddenly enhanced from the near-infrared to the SWIR band [15]. Therefore, the SWIR band is used instead of the NIR band in the MNDWI and the building noise can be effectively suppressed to enhance water bodies. This formula is as follows.

$$
M N D W I=\frac{\rho_{\text {Green }}-\rho_{\text {SWIR2 }}}{\rho_{\text {Green }}+\rho_{\text {SWIR2 }}}
$$


In the formula, $\rho_{\text {Green }}$ denotes the reflectance of the green band, which corresponds to Band 3 of the Sentinel-2 data, and $\rho_{\text {SWIR } 2}$ denotes the reflectance of the SWIR2 band, which corresponds to Band 11 of the Sentinel-2 imagery.

For Sentinel-2, the spatial resolution of the SWIR2 band is $20 \mathrm{~m}$ and the spatial resolutions of the NIR and green bands are both $10 \mathrm{~m}$. Thus, the NDWI can be directly calculated, while the MNDWI cannot be directly determined due to the different spatial resolutions. Compared with the Landsat sensor, the Sentinel-2 sensor has not only improved resolution but also introduced a vegetation-sensitive red-edge band. Therefore, the spectral response mechanism requires analysis to explore the new water index for Sentinel-2 imagery. The TOA reflectance was derived from different land cover types and water types to generate the spectral curves in Figure 2. Figure 2a shows the spectral curves of the ground objects in study area A and Figure $2 \mathrm{~b}$ shows the spectral curves of the water bodies in study areas $\mathrm{B}$, C, and D.
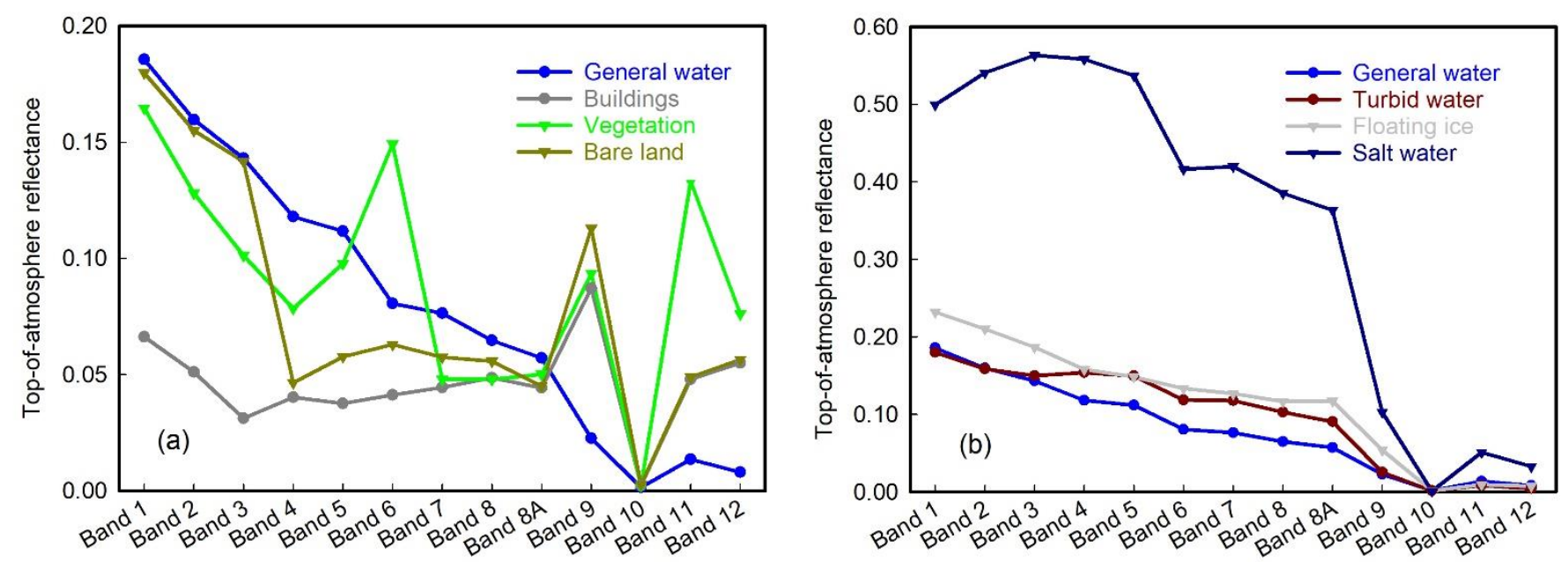

Figure 2. Spectral curves of different land cover and water types. (a) The spectral curves of various land cover types and (b) the spectral curves of various water types.

As shown in Figure 2a, the reflectance of the general water gradually decreases. However, the reflectance values of buildings, vegetation, and bare land increased from the green band (Band 3) to the near-infrared band (Band 8) or from the VRE1 band (Band 5) to the SWIR2 band (Band 11). Therefore, Band 5 and Band 11 can effectively enhance the general water bodies and suppress the buildings and bare land noise. Relative to various water bodies, such as reflected in Figure $2 b$, the reflectance difference between turbid water and floating ice in the green and NIR band is small and the difference in the reflectance of salt water bodies between the VRE1 band (Band 5) and the SWIR2 band (Band 11) is significant. By utilizing the above analysis, Band 5 and Band 11 with same spatial resolution are suitable for constructing a water index for Sentinel-2 imagery. Thus, a novel water index data at $20 \mathrm{~m}$ resolution was constructed using Sentinel-2 imagery, which is reflected in the following formula.

$$
S W I=\frac{\rho_{V R E 1-} \rho_{S W I R 2}}{\rho_{V R E 1+} \rho_{S W I R 2}}
$$

In the formula, SWI represents the Sentinel-2 water index, $\rho_{\mathrm{VRE1}}$ represents the VRE1 band (Band 5 of the Sentinel-2 imagery), and $\rho_{\text {SWIR2 }}$ represents the SWIR2 band (Band 11 of the Sentinel-2 imagery).

\subsection{A Method of Automatic Threshold Determination}

Otsu's method is an efficient and widely used image binarization algorithm that utilizes the maximum variance between classes to distinguish objects and background. That 
is, when the value of the target water body is quite different from that of the background, the water body and the nonwater area can be easily distinguished. The algorithm has been widely used for the automatic threshold extraction of water bodies [13].

The principle of the algorithm is as follows: It is assumed that image $I$ is classified according to the gray level $\{1,2,3, \ldots, M\}$ and the image is divided into thresholds. Then, the probability for each gray level $i$ is determined as follows:

$$
P_{i}=\frac{n_{i}}{N}\left(P_{i} \geq 0\right)
$$

where $N$ denotes the total number of image pixels and $n_{i}$ denotes the number of pixels corresponding to gray level $i$. The probabilities of $C_{0}$ and $C_{1}$ pixels in the entire image are $\omega_{0}$ and $\omega_{1}$, respectively, and the average gray values are $\mu_{0}$ and $\mu_{1}$, respectively.

$$
\begin{gathered}
\omega_{0}=\sum_{i=1}^{T} P_{i} \\
\omega_{1}=\sum_{i=T+1}^{M} P_{i} \\
\mu_{0}=\sum_{i=1}^{T} \frac{i P_{i}}{\omega_{0}} \\
\mu_{1}=\sum_{i=T+1}^{M} \frac{i P_{i}}{\omega_{1}}
\end{gathered}
$$

The total average gray level of the whole image is $U$.

$$
U=\omega_{0} * \mu_{0}+\omega_{1} * \mu_{1}
$$

The interclass variance $(\mathrm{Y})$ of $C_{0}$ and $C_{1}$ is as follows.

$$
\mathrm{Y}=\omega_{0}\left(\mu_{0}-U\right)^{2}+\omega_{1}\left(\mu_{1}-U\right)^{2}
$$

The maximum threshold of the interclass variance $Y$ is the best threshold $\Re_{\text {good }}$ in the study area, as is described as follows.

$$
\Re_{\text {good }}=\operatorname{argmax}(\mathrm{Y})
$$

Water body $W$ was detected by the best threshold $\Re_{\text {good }}$ and it was extracted according to the following rules.

$$
W= \begin{cases}1 & i \geq \Re_{\text {good }} \\ 0 & i<\Re_{\text {good }}\end{cases}
$$

$W=1$ denotes a water body and $W=0$ denotes a nonwater body.

\subsection{The Contrast Value between Water Bodies and Nonwater Bodies}

The purpose of the water index is to enhance the brightness value of water and to suppress nonwater brightness values. By comparing the mean value of the index values in water and nonwater bodies, the ability of the NDWI and SWI to distinguish water bodies from the nonwater areas can be evaluated. The greater the difference of mean value between water and nonwater bodies, the more easily the water body is extracted. Thus, the effectiveness of a water index can be evaluated by comparing the mean value difference between water and nonwater bodies [15]. The formula of the contrast value $(\mathrm{CV})$ is as follows.

$$
C V=E-K
$$

In this case, $E$ denotes the mean value of NDWI or SWI in terms of the water body and $K$ denotes the mean value of NDWI or SWI in terms of the nonwater body. 


\subsection{Accuracy Assessment Method}

Visual interpretation and the quantitative accuracy index are adopted to conduct accuracy verification. The first method is to judge visual effects such as the degree of continuousness and the smoothness of the boundary, which can quickly assess the performance of extraction water bodies. Regarding the detailed differences in water body extraction, the quantitative accuracy index is a widely used method that uses random sample points and high-resolution images. The flow contains three steps: (1) 200 random water sample points and 200 random nonwater sample points are generated for each study area; (2) high-resolution images are used as the reference data to verify and adjust the random sample points and the ground reference points are then generated; (3) ground reference points are superimposed on the water extraction results to verify the accuracy of each random sample point; (4) four widely used accuracy evaluation indices, including producer accuracy, user accuracy, overall accuracy, and Kappa coefficient, are employed to quantitatively assess the water body extraction accuracy.

\section{Results}

\subsection{Comparison of the Water Indices Enhancement Performance}

In order to compare the enhancement performance of NDWI and SWI, the mean values of water indices for the different water types (turbid water, floating ice, and salt water) and nonwater types (building, vegetation, and bare land) are shown in Figure 3. The mean value of the SWI for the water types ranges from 0.78 to 0.89 , while that of NDWI in the water types ranges from 0.18 to 0.41 . For the nonwater types, the mean values of the NDWI and SWI range from -0.24 to -0.07 and from -0.18 to -0.09 , respectively. Compared with the mean value range of water and nonwatery bodies, the difference of the SWI is greater than that of the NDWI, which suggests that the SWI can achieve better enhancement performance.

Water bodies enhanced by the NDWI and SWI in the four study areas are shown in Figure 4. Figure $4 \mathrm{a}$ is a composite image of the Taihu Lake area. The enhanced water bodies utilizing the NDWI and SWI are shown in Figure $4 b, c$, respectively. The NDWI and SWI can effectively distinguish most of the water bodies and the background objects are suppressed. Comparison of the results of the NDWI and SWI for Taihu Lake shows that the difference between water bodies and nonwater bodies using the SWI is more significant than that using the NDWI. This is because the reflectance of polluted water in Taihu Lake is lower in Band 11 than in Band 8 and the SWI can effectively enhance polluted water.

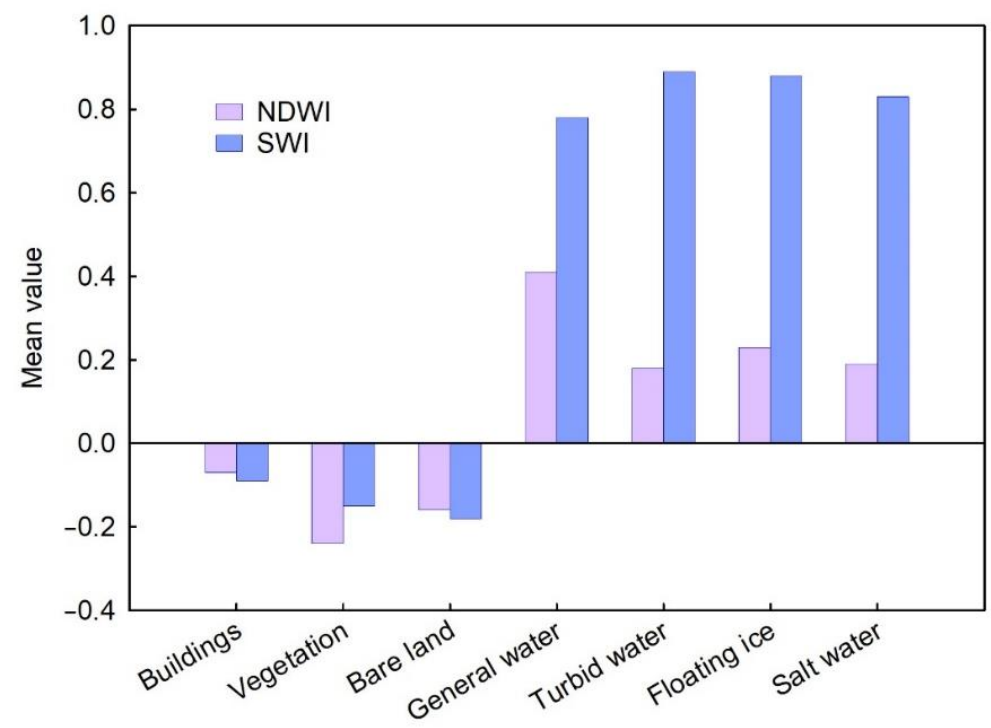

Figure 3. Mean value of SWI and NDWI in different water and nonwater bodies. 
Turbid water is easily confused with buildings and bare land. Figure $4 \mathrm{~d}$ shows the composite image of turbid water in the Yangtze River and the water body enhanced images of NDWI and SWI are shown in Figure 4e,f, respectively. Compared with Figure 4e,f, the performance of the NDWI cannot enhance turbid water from the background in the Yangtze River and coastal waters, but the SWI can effectively separate the water features from the background. Combined with the spectral curve in Figure 2b, it can be observed that the reflectance of turbid water in the green band (Band 3) is consistent with that of the general water body and the reflectance in the NIR band (Band 8) is larger than that in the general water body. Thus, the NDWI value of turbid water is smaller than that of general water bodies. For the SWI, the reflectance of turbid water in the vegetation-sensitive red-edge band (Band 5) is greater than that of general water bodies and the reflectance in the SWIR band (Band 11) is consistent with that of general water bodies. Compared with the general water bodies, the mean value of turbid water is 0.89 by using SWI calculations, which makes it easier to distinguish turbid water from buildings and bare soil.

Chaka Salt Lake is a shallow salt lake. Figure $4 \mathrm{~g}$ shows a composite image of Chaka Salt Lake. The enhanced images of the water body were obtained by using the NDWI and SWI (Figure $4 \mathrm{~h}, \mathrm{i}$, respectively). The results show that the NDWI cannot effectively enhance most of the water body information, while the water bodies can be highlighted using the SWI. This is because the reflectance difference between the green band (Band 3) and NIR band (Band 8) is smaller than that between the vegetation-sensitive red-edge band (Band 5) and SWIR band (Band 11), which renders the mean value of the SWI larger than that of the NDWI in Chaka Salt Lake.

The Sentinel-2A image of Chain Lake is shown in Figure $4 \mathrm{j}$ and flowing ice is present in Chain Lake. The enhanced images of the water body were obtained by using NDWI and SWI (Figure $4 \mathrm{k}, \mathrm{l}$, respectively). As we can see from the enhanced water body performance, the NDWI misses some of the floating ice, while the SWI can effectively highlight floating ice. Combined with Figure 2, the reflectance of floating ice is similar to that of general water bodies from the visible light band (Band 3 and Band 5) to the NIR band (Band 8) and the reflectance of floating ice is larger than that of general water. In the SWIR band (Band 11), the reflectance of floating ice is slightly different from that of general water and so the NDWI value of floating ice is smaller than that of general water, with a mean value of 0.23 (Figure 3). The SWI value of floating ice is larger than that of general water and the mean value is 0.88 (Figure 3 ). Therefore, the SWI can achieve better performance than the NDWI in terms of extracting floating ice.

\subsection{Validation of the Effectiveness of the Water Index}

In order to analyze the accuracy of the NDWI and SWI, the contrast value derived from the mean values of NDWI or SWI is calculated to evaluate the separation between water bodies and nonwater bodies. The mean values and contrast values of the water bodies and nonwater bodies for the NDWI and SWI in each study area are summarized in Table 3. The mean value of the SWI in terms of water bodies is higher than that of the NDWI and the difference between the mean NDWI value and the mean SWI value in terms of nonwater bodies is not significant. Therefore, the contrast values of SWI are higher than those of NDWI in each study area, which suggests that the SWI is a more robust and the more effective water index for enhancing water information features in Sentinel-2 imagery. 

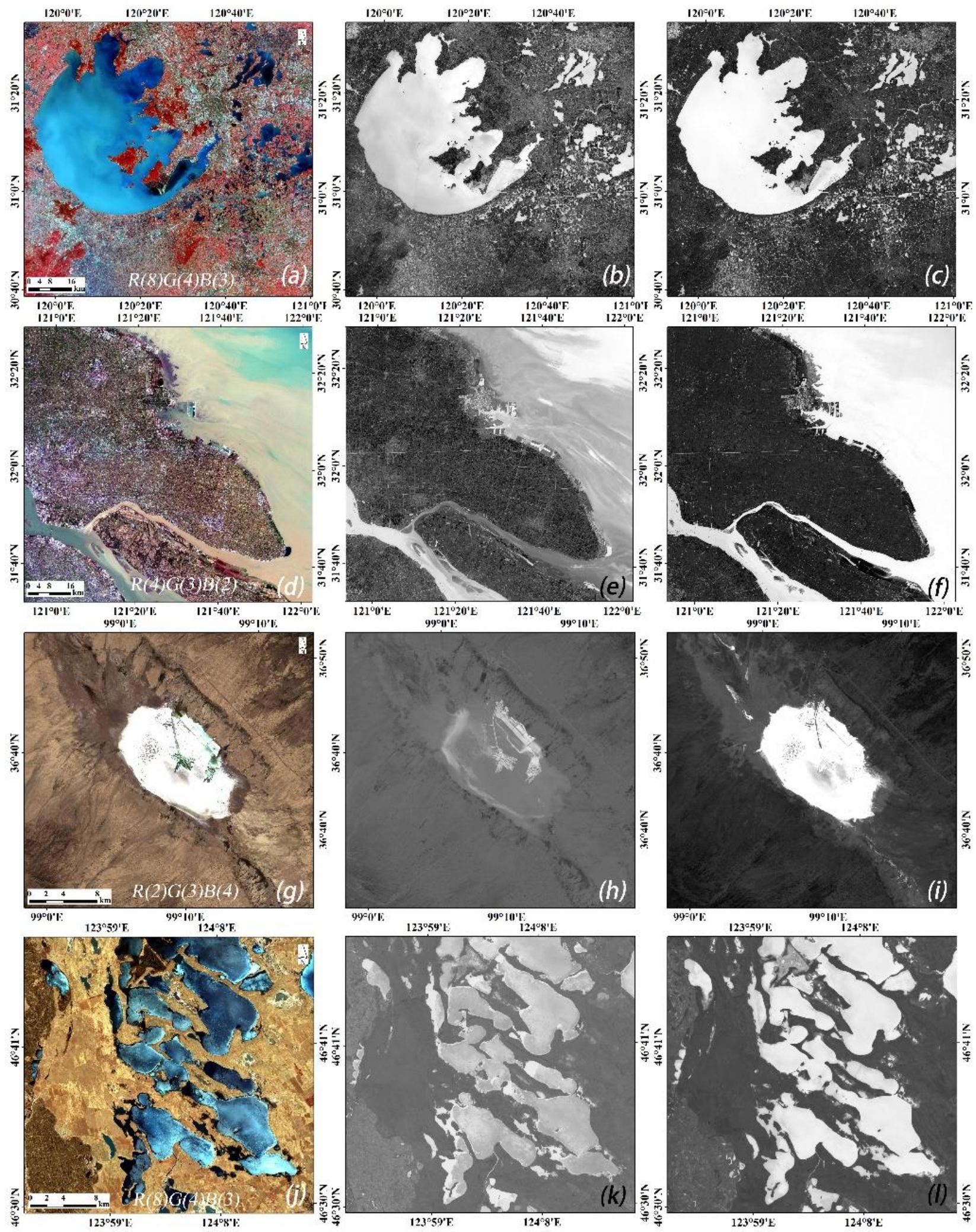

Figure 4. Water bodies enhanced by the NDWI and SWI in the four study areas. ((a) Taihu Lake composite image (R: Band 8; G: Band 4; B: Band 3), (b) NDWI of Taihu Lake, (c) SWI of Taihu Lake, (d) Yangtze River composite image (R: Band 4; G: Band 3; B: Band 2), (e) NDWI of the Yangtze River, (f) SWI of the Yangtze River, (g) Chaka Salt Lake composite image (R: Band 2; G: Band 3; B: Band 4), (h) NDWI of Chaka Salt Lake, (i) SWI of Chaka Salt Lake, (j) Chain Lake composite image (R: Band 8; G: Band 4; B: Band 3), (k) NDWI of Chain Lake, and (1) SWI of Chain Lake)). 
Table 3. Sample means and contrast values.

\begin{tabular}{ccccccc}
\hline Study Area & Water & $\begin{array}{c}\text { NDWI } \\
\text { Nonwater }\end{array}$ & $\boldsymbol{C V}$ & Water & $\begin{array}{c}\text { SWI } \\
\text { Nonwater }\end{array}$ & $\boldsymbol{C V}$ \\
\hline Taihu Lake & 0.38 & -0.20 & 0.58 & 0.78 & -0.12 & 0.90 \\
Yangtze River & 0.22 & -0.23 & 0.45 & 0.89 & -0.09 & 0.98 \\
Chaka Salt Lake & 0.13 & -0.21 & 0.34 & 0.81 & -0.17 & 0.98 \\
Chain Lake & 0.34 & -0.26 & 0.60 & 0.84 & -0.31 & 1.15 \\
\hline
\end{tabular}

Figure 5 shows the box plots of the NDWI and SWI in terms of water bodies and nonwater bodies. Figure $5 \mathrm{a}-\mathrm{d}$ are the study areas of Taihu Lake, Yangtze River, Chaka Salt Lake, and Chain Lake, respectively. The plots show that the NDWI and SWI can distinguish most of the water bodies and nonwater bodies; however, the maximum or minimum NDWI values for the nonwater areas almost overlap with the standard deviation of the NDWI values for the water bodies, while the maximum or minimum SWI values for the nonwater areas can be effectively distinguished from the SWI values for the water bodies based on the standard deviation. By performing analysis of the box plots, the results suggest that the NDWI will cause some misclassifications of water and nonwater bodies, while the SWI can effectively separate different water body types and nonwater bodies.
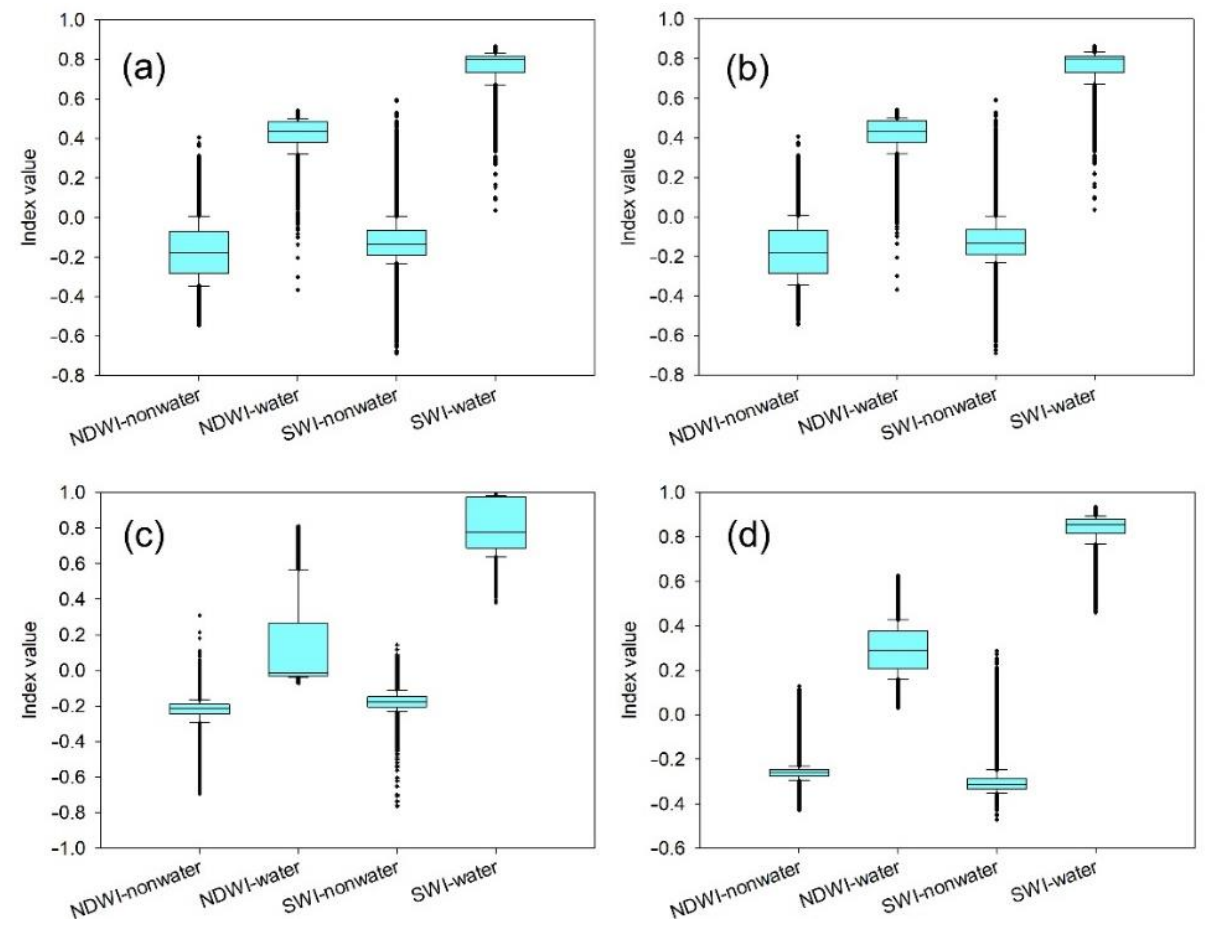

Figure 5. Box plots of the NDWI and SWI values in the four study areas. ((a-d) show the box plots for Taihu Lake, Yangtze River, Chaka Salt Lake, and Chain Lake, respectively).

\subsection{Water Body Extraction Performance}

Otsu's method can automatically determine the segmentation threshold based on the image histogram, which is widely used in water body extraction in combination with water indices [38]. The water body extraction results using Otsu's method are shown in Figure 6. Panels (a), (d), (g), and (j) correspond to the NDWI water extraction results for Taihu Lake, Yangtze River, Chaka Salt Lake, and Chain Lake study areas, respectively. Similarly, panels (c), (f), (i), and (l) correspond to the SWI water extraction results for the four study areas. The blue regions of the four study areas in (c), (f), (i), and (l) correspond to the parts of the water bodies extracted by both the NDWI and SWI and the red regions correspond to the parts of the water bodies that the SWI extracted but were missed by the extraction performed with NDWI. 
Figure 6a-c show that the SWI and NDWI can effectively extract most of the water bodies; however, the NDWI misses some water bodies in narrow rivers, which suggests that the NDWI easily confuses water bodies and nonwater bodies along these rivers. Figure $6 \mathrm{~d}-\mathrm{f}$ show that the NDWI cannot extract water bodies with high sediment concentrations because the NDWI easily misclassifies such water as buildings, bare soil, etc. However, the SWI can more effectively extract both turbid and nonturbid water in the Yangtze River and offshore. Figure $6 \mathrm{~g}-\mathrm{i}$ show that the NDWI has a poor extraction performance for saline water bodies, while the SWI can effectively extract the whole salt lake. Moreover, because the SWI is sensitive to water bodies in the SWIR band, a small amount of water bodies on bare land can also be effectively identified. Figure $6 j-1$ show that both the NDWI and the SWI can extract most of the water bodies with floating ice. Due to the NDWI value difference between floating ice and the background being smaller than that of the SWI, the floating ice is easily confused with the high-reflectance bare ground in the NDWI results, while it is accurately extracted in the SWI results.

\subsection{Accuracy Assessment}

For the water extraction results of the four study areas in Figure 6, visual interpretation and a quantitative accuracy index are used to conduct accuracy assessments. The performance of water body extraction with different water indices in Chaka Salt Lake and Chain Lake show great differences; therefore, visual evaluation suggests that the extraction accuracy of the SWI is better than that of the NDWI in these two study areas. For Chaka Salt Lake, the SWI can not only extract salt water more completely than the NDWI but also the sensitivity of the SWI with respect to water turbidity renders it capable of distinguishing a small amount of water from bare soil; thus, the SWI has a better extraction performance than the NDWI in this regard. For Chain Lake, the smoothness and continuity of the SWI for extracting the lake boundary is improved compared to the NDWI extraction; thus, the water body extraction accuracy of the SWI is higher than that of the NDWI.

The study areas of Taihu Lake and the Yangtze River cover various land cover types and water body types. The quantitative accuracy index method is employed to assess the water body extraction accuracy and the results are shown in Table 4. For the two study areas, the producer's accuracy, user's accuracy, overall accuracy, and Kappa coefficient of the SWI are superior to those of the NDWI, which suggests that the SWI can achieve better extraction performance than that of the NDWI. For Taihu Lake, since both indices can accurately extract most of the water, the differences in terms of the quantitative accuracy index between the NDWI and the SWI are small. For the Yangtze River, the accuracy of the NDWI is obviously lower than that of the SWI. This is because the NDWI classifies water bodies containing sediment as bare soil, buildings, or other nonwater land cover types, while the SWI can accurately extract these water body types. These results indicate that the extraction accuracy of the SWI is higher than that of the NDWI in the Yangtze River study area.

Table 4. Accuracy verification in Taihu lake and Yangtze river.

\begin{tabular}{cccccccc}
\hline \multirow{2}{*}{ Study Area } & & \multicolumn{2}{c}{ Producer's Accuracy } & \multicolumn{2}{c}{ User's Accuracy } & \multicolumn{2}{c}{$\begin{array}{c}\text { Overall } \\
\text { Precision } \\
\text { Accuracy }\end{array}$} \\
& & Water & Nonwater & Water & Nonwater & Kappa \\
Coefficient
\end{tabular}



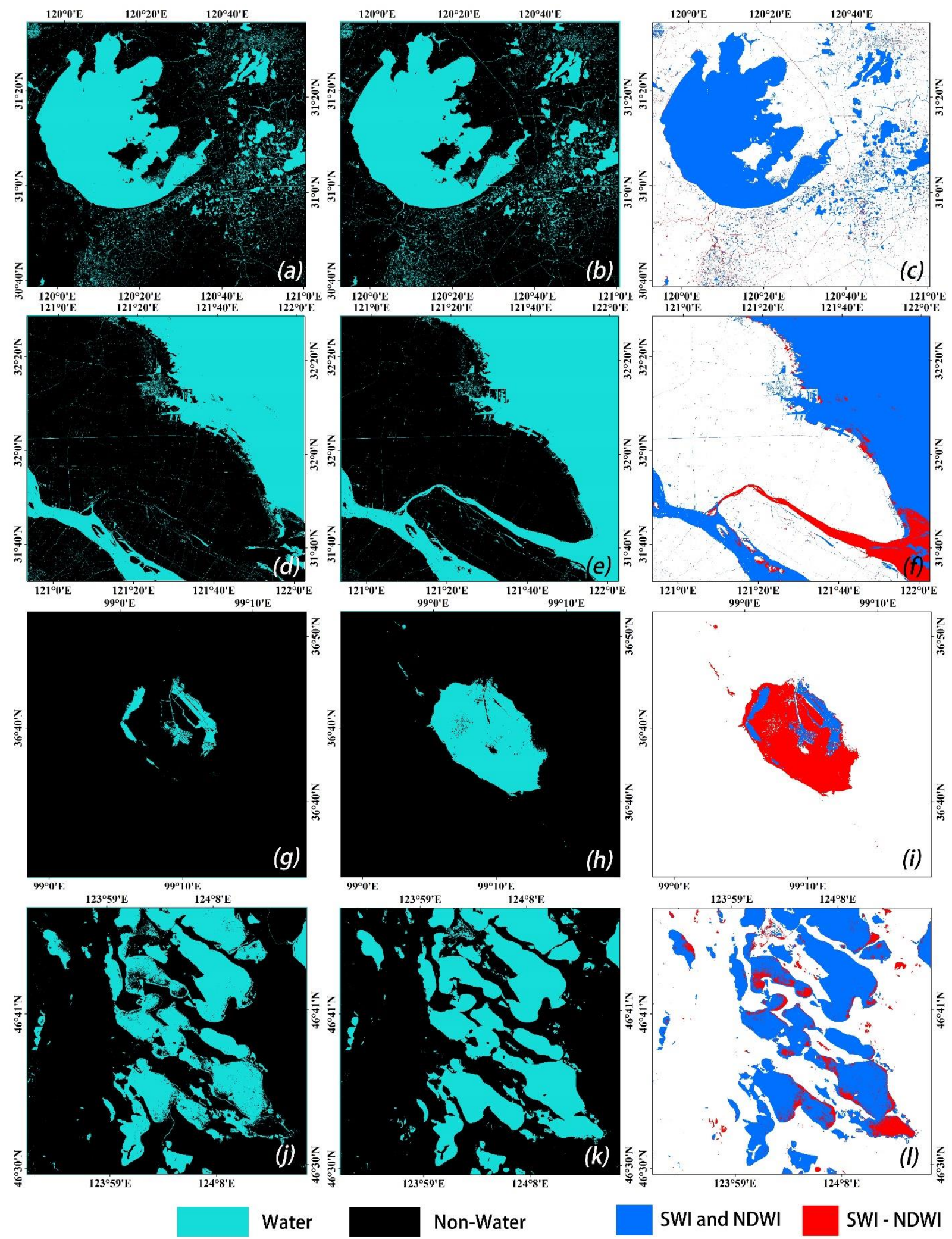

Figure 6. Water extraction performances and differences between the NDWI and SWI. $((\mathbf{a}, \mathbf{d}, \mathbf{g}, \mathbf{j})$ represent the water bodies extracted by the NDWI in the Taihu Lake, Yangtze River, Chaka Salt Lake, and Chain Lake images, respectively. (b,e,h,k) represent the water bodies extracted by the SWI in the Taihu Lake, Yangtze River, Chaka Salt Lake, and Chain Lake images, respectively. (c,f,i,l) show the differences between the NDWI and SWI in the Taihu Lake, Yangtze River, Chaka Salt Lake, and Chain Lake images, respectively). 


\section{Discussion}

Sentinel-2 produces widely used remote sensor imagery with high spatial resolution and a short return period and this imagery has great application potential in large-scale surface water mapping $[39,40]$. By investigating the spectral response mechanism of Sentinel-2, a new water index, namely, the SWI, was proposed to extract various water body types with Otsu's method. Moreover, the extraction performance and precision suggest that the novel method is simple and effective. However, there is still some matters with respect to the application scope that requires discussion.

Firstly, the spatial resolution and selected SWI response band were balanced. The highest spatial resolution of Sentinel-2 is $10 \mathrm{~m}$, while Band 5 and Band 11 with $20 \mathrm{~m}$ spatial resolution were employed to establish the SWI to enhance the water body information. By comparing the enhancement performance of the NDWI at a $10 \mathrm{~m}$ spatial resolution with that of the SWI at a $20 \mathrm{~m}$ spatial resolution (Figure 7), the results demonstrate that the enhancement performance of the SWI is better than that of the NDWI (Figure $7 \mathrm{~b}, \mathrm{c}$ ). Compared with the extraction results of the NDWI, the extracted water bodies of the SWI are more complete and accurate and a comparison (Figure 7f) shows that the river channels are missed using NDWI at a 10-m resolution [41]. In addition, a previous study generated $10 \mathrm{~m}$ MNDWI from Sentinel-2 imagery by sharpening the SWIR band and the results demonstrated that MNDWI can produce more accurate extraction results [32]. However, the complexity of the pansharpening algorithm restricts the efficiency of water body mapping. Therefore, from the perspective of water extraction performance and efficiency comparing the various water indices, the selection of response bands is more important than spatial resolution.

Secondly, the applicability of the proposed method in urban areas was assessed. Due to the complex background of urban areas and building shadows, it is a great challenge to use water indices to extract water bodies in urban areas [42]. In order to investigate the applicability of the SWI in urban areas, four cities surrounding Taihu Lake, namely, Suzhou, Jiaxing, Wuxi, and Huzhou, were selected to conduct the water body extraction performance comparison using the NDWI and SWI. The extraction results are shown in Figure 8. Blue regions indicate water bodies extracted by both the NDWI and SWI; red regions indicate water bodies extracted by the SWI but not by the NDWI; and purple regions indicate water bodies extracted by the NDWI but not by the SWI. Hence, the blue and red regions represent water bodies extracted by the SWI and the blue and purple regions indicate water bodies extracted by the NDWI.

The results of water body extraction in urban areas (Figure 8) have yielded several findings: (1) Large water bodies can be extracted well with both the SWI and NDWI, especially the lakes and connected open water bodies in Figure 8b,c; (2) wide river channels are significantly missed using the NDWI in Figure $8 \mathrm{~d}$ but are accurately extracted by the SWI; (3) severe mixing of building shadows and water bodies occurs when using the NDWI in Figure 8(a1,c1), which may indicate that the NDWI has difficulty eliminating shadow noise; (4) the NDWI can accurately extract small water bodies and narrow river channels in Figure 8(b1,c1). This pattern is due to the difference in the resolution between the SWI and the NDWI and the SWI cannot effectively extract the subpixel water bodies from the super-resolution maps. Therefore, the SWI can accurately extract large water bodies and wide river channels in urban areas but cannot effectively extract narrow rivers because the SWI is calculated based on $20 \mathrm{~m}$ response bands. 

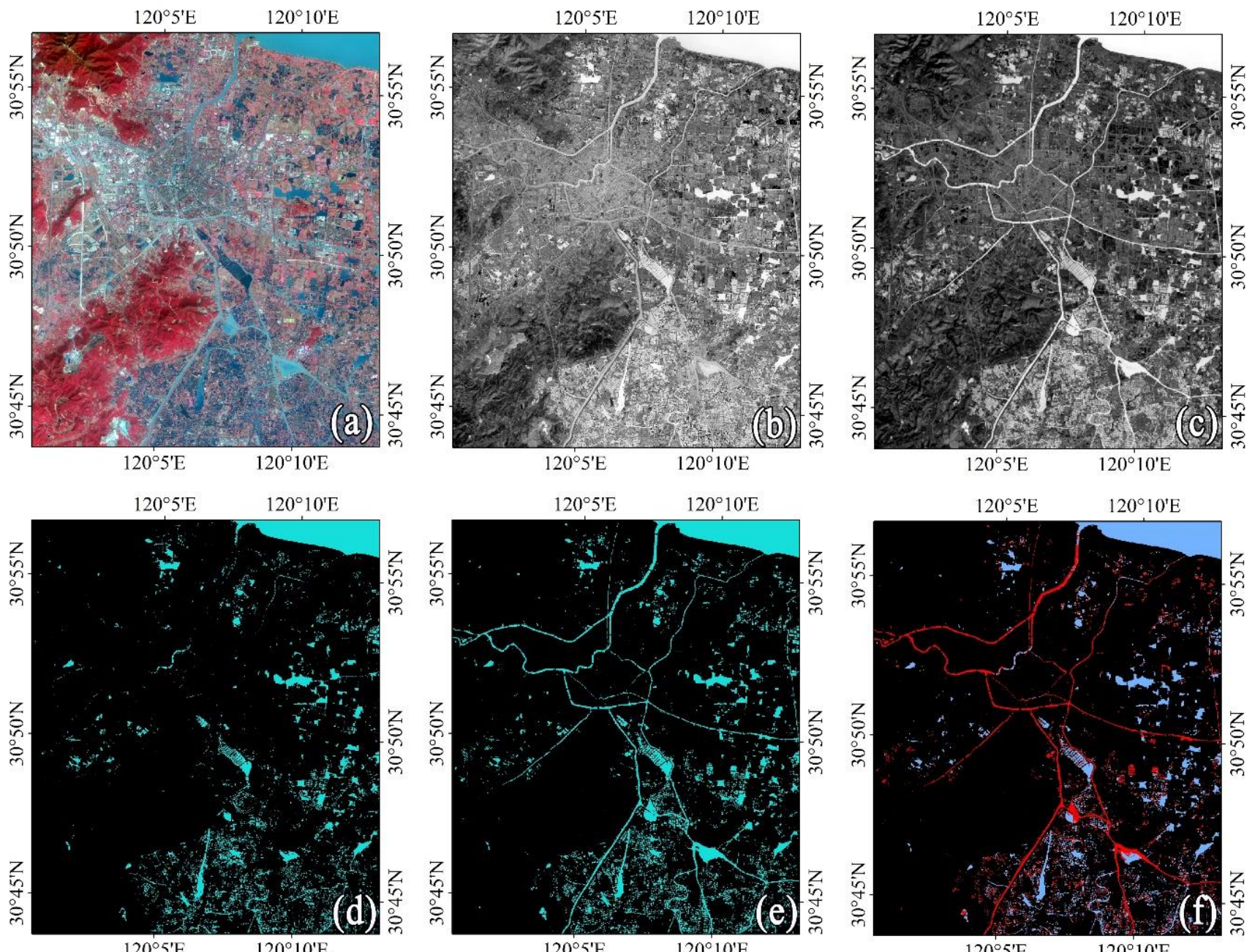

\section{Water Non-Water}

$120^{\circ} 5^{\prime} \mathrm{E}$

$120^{\circ} 10^{\prime} \mathrm{E}$

SWI and NDWI $120^{\circ} 5^{\prime} \mathrm{E}$

$120^{\circ} 10^{\prime} \mathrm{E}$

SWI - NDWI

Figure 7. The performance of water body enhancement and extraction. ((a) original image, (b) water body enhancement using NDWI, (c) water body enhancement using SWI, (d) water body extraction using NDWI, (e) water body extraction using SWI, and (f) extraction performance comparison).

There are two reasons why SWI can result in better extraction performance regarding the various water body types. The first one is to take into account the unique band characteristic of Sentinel-2 and, then, analyze the spectral response mechanism to determine the sensitive characteristic bands to highlight the water body from the background. The second one is to employ the Otsu algorithm to automatically identify the segmentation threshold and, following that, the water body and nonwater body can be separated clearly. The determination of the sensitive characteristic band is critical to achieve better water body extraction performance and the new water index, namely SWI, has been confirmed to enhance various water body types. Therefore, this method has application potential for larger-scale surface water mapping.

The limitation of this method is the relatively low spatial resolution. Currently, the highest spatial resolution of Sentinel-2 is $10 \mathrm{~m}$, while the sensitive characteristic bands selected by this method is $20 \mathrm{~m}$. Therefore, some narrow rivers and small lakes cannot be accurately extracted in urban areas. Although there are some documents that possess adopted image fusion methods to improve spatial resolution [32], they also face two challenges: (1) The complexity of fusion methods restricts the efficiency of large-scale surface water extraction; (2) changes in the spectral response mechanism after fusion will affect the performance of water body enhancement. Therefore, efficient and reliable 
image fusion methods for Sentinel-2 requires further development in order to improve the accuracy of water body extraction in large scales.
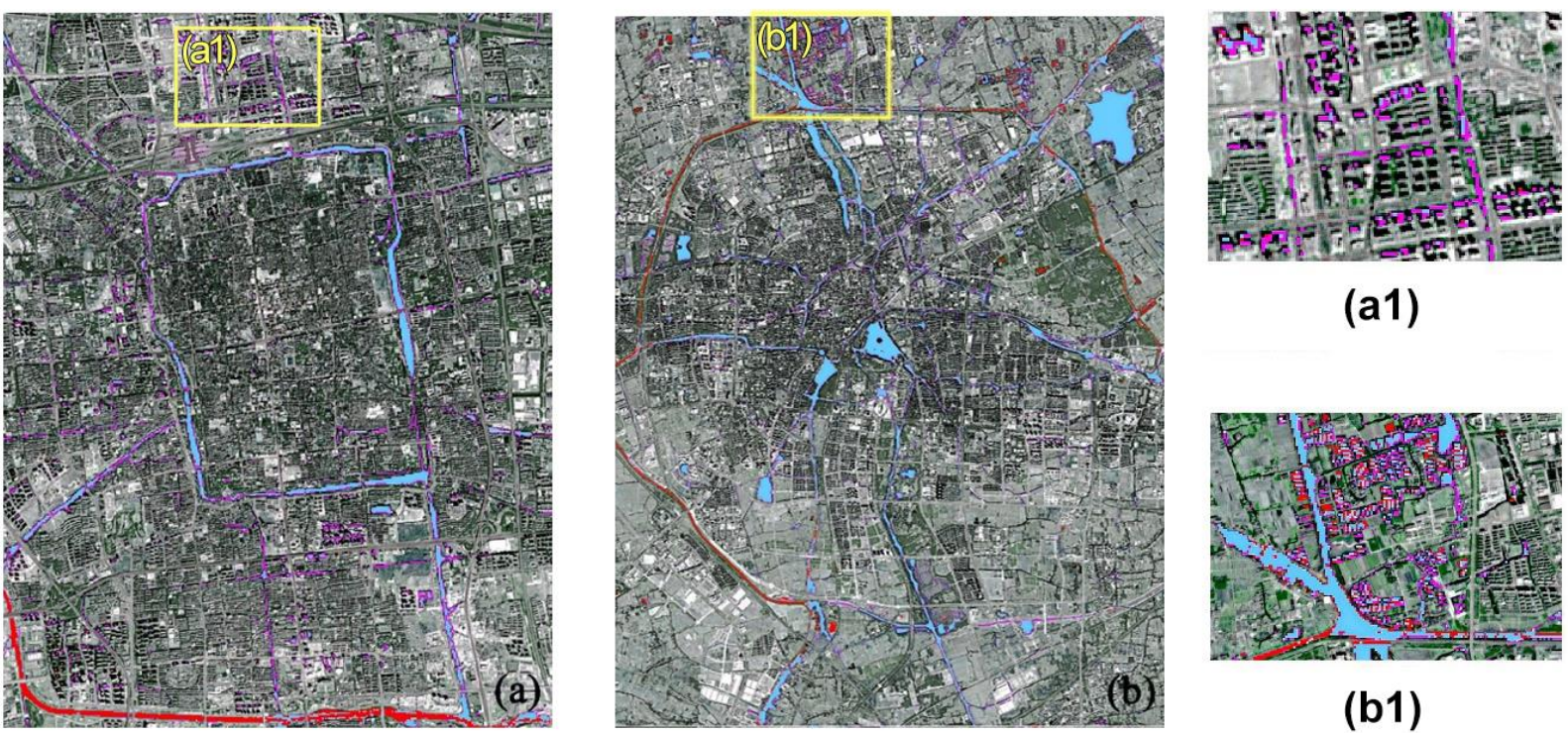

(a1)

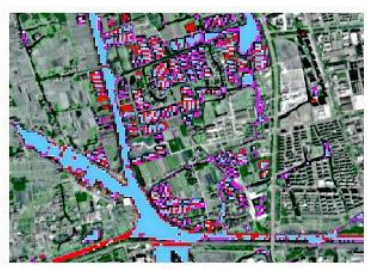

(b1)
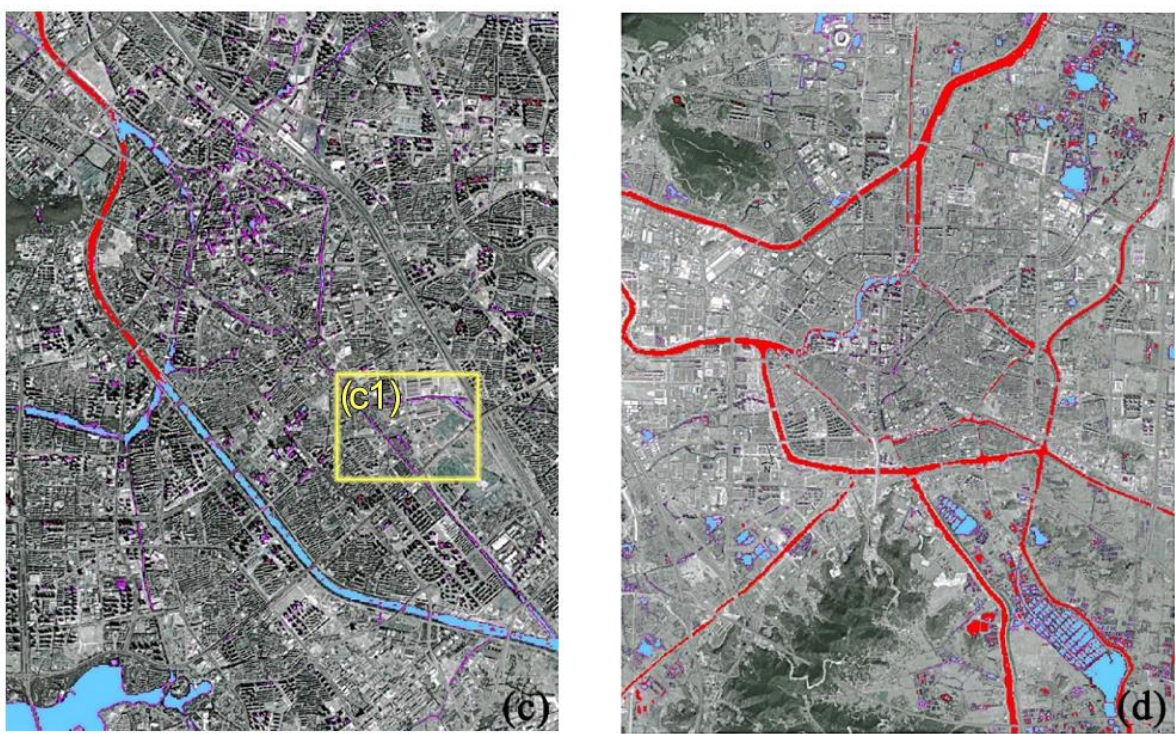

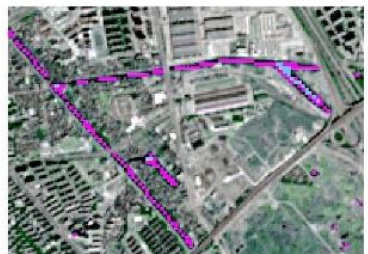

(c1)

SWI and NDWI

SWI - NDWI

\section{NDWI-SWI}

Figure 8. Performance comparison of water extraction in urban areas. ((a) Suzhou, (b) Jiaxing, (c) Wuxi, (d) Huzhou, (a1) building shadows, (b1) small water body, (c1) narrow river channel).

\section{Conclusions}

An effective water body extraction method for Sentinel-2 contributes to large-scale water body mapping to understand surface water dynamic changes. This paper fully considers the unique band characteristics and analyzes the spectral response mechanism of Sentinel-2A data. A new water index, namely, the SWI, is proposed. The enhancement and extraction performances of various water body types from a typical study area are compared and the extraction accuracy is verified. The conclusions can be summarized as follows:

(1) Compared with NDWI, the SWI calculated using vegetation-sensitive red-edge and SWIR bands can achieve better enhancement performance for various water body types, including purer water, turbid water, salt water, and floating ice. The contrast values between water bodies and nonwater bodies of the SWI are larger than those of 
the NDWI, which indicates that the SWI can effectively separate different types of water bodies and nonwater bodies;

(2) The integration of the SWI and Otsu algorithm is an effective method for accurately extracting various water body types. Visual evaluation suggests that the extraction accuracy of the SWI is better than that of the NDWI for Chaka Salt Lake and Chain Lake. Quantitative assessment shows that the overall accuracy of water body extraction using SWI for Taihu Lake and the Yangtze River (92.75\% and 93\%, respectively) is higher than that using the NDWI;

(3) Although the water body extraction spatial resolution of the SWI is $20 \mathrm{~m}$, the extraction performance of the SWI is better than that of the NDWI with a resolution of $10 \mathrm{~m}$. Moreover, the new method can effectively extract large water bodies and wide river channels by eliminating shadow noise in urban areas.

Author Contributions: Conceptualization and methodology, W.J. and Y.N.; data collection, H.J. and X.Q., data collection, W.J. and X.L.; data analysis, W.J. and Y.N.; writing-original draft preparation, Z.P.; review and editing, G.H., J.L., K.Y., and J.F. All authors have read and agreed to the published version of the manuscript.

Funding: This research was funded by the National Natural Science Foundation of China (51779269), the National Key Research and Development Program of China (2017YFB0504105 and 2017YFA0605003), and the Innovation Talent Project of Research Center of Flood and Drought Disaster Reduction of the Ministry of Water Resources.

Institutional Review Board Statement: Not applicable.

Informed Consent Statement: Not applicable.

Data Availability Statement: Not applicable.

Conflicts of Interest: The authors declare no conflict of interest.

\section{References}

1. Feng, M.; Sexton, J.O.; Channan, S.; Townshend, J.R. A global, high-resolution (30-m) inland water body dataset for 2000: First results of a topographic-spectral classification algorithm. Int. J. Digit. Earth. 2016, 9, 113-133. [CrossRef]

2. Sekertekin, A. A Survey on Global Thresholding Methods for Mapping Open Water Body Using Sentinel-2 Satellite Imagery and Normalized Difference Water Index. Arch. Comput. Method Eng. 2019, 13, 13. [CrossRef]

3. Jiang, W.; He, G.; Pang, Z.; Guo, H.; Long, T.; Ni, Y. Surface water map of China for 2015 (SWMC-2015) derived from Landsat 8 satellite imagery. Remote Sens. Lett. 2020, 11, 265-273. [CrossRef]

4. Yue, H.; Li, Y.; Qian, J.X.; Liu, Y. A new accuracy evaluation method for water body extraction. Int. J. Remote Sens. 2020, 41, 1-32. [CrossRef]

5. Jiang, W.; He, G.; Long, T.; Ni, Y.; Liu, H.; Peng, Y.; Lv, K.; Wang, G. Multilayer Perceptron Neural Network for Surface Water Extraction in Landsat 8 OLI Satellite Images. Remote Sens. 2018, 10, 755. [CrossRef]

6. Yamazaki, D.; Trigg, M.A. HYDROLOGY The dynamics of Earth's surface water. Nature 2016, 540, 348-349. [CrossRef]

7. Donchyts, G.; Baart, F.; Winsemius, H.; Gorelick, N.; Kwadijk, J.; van de Giesen, N. Earth's surface water change over the past 30 years. Nat. Clim. Chang. 2016, 6, 810-813. [CrossRef]

8. Guo, H.; He, G.; Jiang, W.; Yin, R.; Yan, L.; Leng, W. A Multi-Scale Water Extraction Convolutional Neural Network (MWEN) Method for GaoFen-1 Remote Sensing Images. ISPRS Int. J. Geo-Inform. 2020, 9, 189. [CrossRef]

9. Jiang, W.; He, G.; Pang, Z.; Long, T.; Fu, J.; Guo, H.; Ni, Y. Verification and analysis of surface water in China based on Landsat8 OLI images. IOP Conf. Ser. Earth Environ. Sci. 2020, 502, 012030. [CrossRef]

10. Pekel, J.F.; Cottam, A.; Gorelick, N.; Belward, A.S. High-resolution mapping of global surface water and its long-term changes. Nature 2016, 540, 418-422. [CrossRef] [PubMed]

11. Ji, L.Y.; Gong, P.; Geng, X.R.; Zhao, Y.C. Improving the Accuracy of the Water Surface Cover Type in the $30 \mathrm{~m}$ FROM-GLC Product. Remote Sens. 2015, 7, 13507-13527. [CrossRef]

12. Liao, A.P.; Chen, L.J.; Chen, J.; He, C.Y.; Cao, X.; Chen, J.; Peng, S.; Sun, F.D.; Gong, P. High-resolution remote sensing mapping of global land water. Sci. China-Earth Sci. 2014, 57, 2305-2316. [CrossRef]

13. Sekertekin, A. Potential of global thresholding methods for the identification of surface water resources using Sentinel-2 satellite imagery and normalized difference water index. J. Appl. Remote Sens. 2019, 13. [CrossRef]

14. McFeeters, S.K. The use of the normalized difference water index (NDWI) in the delineation of open water features. Int. J. Remote Sens. 1996, 17, 1425-1432. [CrossRef] 
15. Xu, H.Q. Modification of normalised difference water index (NDWI) to enhance open water features in remotely sensed imagery. Int. J. Remote Sens. 2006, 27, 3025-3033. [CrossRef]

16. Wang, Z.F.; Liu, J.G.; Li, J.B.; Zhang, D.D. Multi-Spectral Water Index (MuWI): A Native 10-m Multi-Spectral Water Index for Accurate Water Mapping on Sentinel-2. Remote Sens. 2018, 10, 1643. [CrossRef]

17. Du, Z.; Li, W.; Zhou, D.; Tian, L.; Ling, F.; Wang, H.; Gui, Y.; Sun, B. Analysis of Landsat-8 OLI imagery for land surface water mapping. Remote Sens. Lett. 2014, 5, 672-681. [CrossRef]

18. Isikdogan, F.; Bovik, A.C.; Passalacqua, P. Surface Water Mapping by Deep Learning. IEEE J. Sel. Top. Appl. Earth. Observ. Remote Sens. 2017, 10. [CrossRef]

19. Huang, C.; Chen, Y.; Wu, J.P.; Li, L.Y.; Liu, R. An evaluation of Suomi NPP-VIIRS data for surface water detection. Remote Sens. Lett. 2015, 6, 155-164. [CrossRef]

20. Huang, C.; Chen, Y.; Zhang, S.; Li, L.; Shi, K.; Liu, R. Surface Water Mapping from Suomi NPP-VIIRS Imagery at $30 \mathrm{~m}$ Resolution via Blending with Landsat Data. Remote Sens. Lett. 2016, 8, 631. [CrossRef]

21. Bijeesh, T.V.; Narasimhamurthy, K.N. Surface water detection and delineation using remote sensing images: A review of methods and algorithms. Sustain. Water Resour. Manag. 2020, 6. [CrossRef]

22. Huang, X.; Xie, C.; Fang, X.; Zhang, L.P. Combining Pixel- and Object-Based Machine Learning for Identification of Water-Body Types From Urban High-Resolution Remote-Sensing Imagery. IEEE J. Sel. Top. Appl. Earth. Observ. Remote Sens. 2015, 8, 2097-2110. [CrossRef]

23. Feyisa, G.L.; Meilby, H.; Fensholt, R.; Proud, S.R. Automated Water Extraction Index: A new technique for surface water mapping using Landsat imagery. Remote Sens. Environ. 2014, 140, 23-35. [CrossRef]

24. Zhou, Y.; Dong, J.W.; Xiao, X.M.; Xiao, T.; Yang, Z.Q.; Zhao, G.S.; Zou, Z.H.; Qin, Y.W. Open Surface Water Mapping Algorithms: A Comparison of Water-Related Spectral Indices and Sensors. Water 2017, 9, 256. [CrossRef]

25. Lu, S.L.; Wu, B.F.; Yan, N.N.; Wang, H. Water body mapping method with HJ-1A/B satellite imagery. Int. J. Appl. Earth Obs. Geoinf. 2011, 13, 428-434. [CrossRef]

26. Fisher, A.; Danaher, T. A Water Index for SPOT5 HRG Satellite Imagery, New South Wales, Australia, Determined by Linear Discriminant Analysis. Remote Sens. 2013, 5, 5907-5925. [CrossRef]

27. Zhang, Z.Y.; He, H.X.; Yu, C.H.; Zhang, W.; Li, L.Y.; Meng, L.K. Using the modified two-mode method to identify surface water in Gaofen-1 images. J. Appl. Remote Sens. 2018, 13, 16. [CrossRef]

28. Drusch, M.; Del Bello, U.; Carlier, S.; Colin, O.; Fernandez, V.; Gascon, F.; Hoersch, B.; Isola, C.; Laberinti, P.; Martimort, P.; et al. Sentinel-2: ESA's Optical High-Resolution Mission for GMES Operational Services. Remote Sens. Environ. 2012, $120,25-36$. [CrossRef]

29. Yang, X.C.; Qin, Q.M.; Yesou, H.; Ledauphin, T.; Koehl, M.; Grussenmeyer, P.; Zhu, Z. Monthly estimation of the surface water extent in France at a 10-m resolution using Sentinel-2 data. Remote Sens. Environ. 2020, 244, 23. [CrossRef]

30. Wieland, M.; Martinis, S. Large-scale surface water change observed by Sentinel-2 during the 2018 drought in Germany. Int. J. Remote Sens. 2020, 41, 4740-4754. [CrossRef]

31. Liu, Q.H.; Huang, C.; Shi, Z.L.; Zhang, S.Q. Probabilistic River Water Mapping from Landsat-8 Using the Support Vector Machine Method. Remote Sens. 2020, 12, 1374. [CrossRef]

32. Du, Y.; Zhang, Y.H.; Ling, F.; Wang, Q.M.; Li, W.B.; Li, X.D. Water Bodies' Mapping from Sentinel-2 Imagery with Modified Normalized Difference Water Index at 10-m Spatial Resolution Produced by Sharpening the SWIR Band. Remote Sens. 2016, 8, 354. [CrossRef]

33. Yang, X.C.; Chen, L. Evaluation of automated urban surface water extraction from Sentinel-2A imagery using different water indices. J. Appl. Remote Sens. 2017, 11, 11. [CrossRef]

34. Yang, X.C.; Zhao, S.S.; Qin, X.B.; Zhao, N.; Liang, L.G. Mapping of Urban Surface Water Bodies from Sentinel-2 MSI Imagery at $10 \mathrm{~m}$ Resolution via NDWI-Based Image Sharpening. Remote Sens. 2017, 9, 596. [CrossRef]

35. van der Meer, F.D.; van der Werff, H.M.A.; van Ruitenbeek, F.J.A. Potential of ESA's Sentinel-2 for geological applications. Remote Sens. Environ. 2014, 148, 124-133. [CrossRef]

36. Berger, M.; Moreno, J.; Johannessen, J.A.; Levelt, P.F.; Hanssen, R.F. ESA's sentinel missions in support of Earth system science. Remote Sens. Environ. 2012, 120, 84-90. [CrossRef]

37. Caballero, I.; Ruiz, J.; Navarro, G. Sentinel-2 Satellites Provide Near-Real Time Evaluation of Catastrophic Floods in the West Mediterranean. Water 2019, 11, 2499. [CrossRef]

38. Bishop-Taylor, R.; Sagar, S.; Lymburner, L.; Alam, I.; Sixsmith, J. Sub-Pixel Waterline Extraction: Characterising Accuracy and Sensitivity to Indices and Spectra. Remote Sens. 2019, 11, 2984. [CrossRef]

39. Bioresita, F.; Puissant, A.; Stumpf, A.; Malet, J.P. Fusion of Sentinel-1 and Sentinel-2 image time series for permanent and temporary surface water mapping. Int. J. Remote Sens. 2019, 40, 9026-9049. [CrossRef]

40. Yang, X.C.; Chen, Y.; Wang, J.Z. Combined use of Sentinel-2 and Landsat 8 to monitor water surface area dynamics using Google Earth Engine. Remote Sens. Lett. 2020, 11, 687-696. [CrossRef]

41. Bie, W.J.; Fei, T.; Liu, X.Y.; Liu, H.Z.; Wu, G.F. Small water bodies mapped from Sentinel-2 MSI (MultiSpectral Imager) imagery with higher accuracy. Int. J. Remote Sens. 2020, 41, 7912-7930. [CrossRef]

42. Yang, X.C.; Qin, Q.M.; Grussenmeyer, P.; Koehl, M. Urban surface water body detection with suppressed built-up noise based on water indices from Sentinel-2 MSI imagery. Remote Sens. Environ. 2018, 219, 259-270. [CrossRef] 